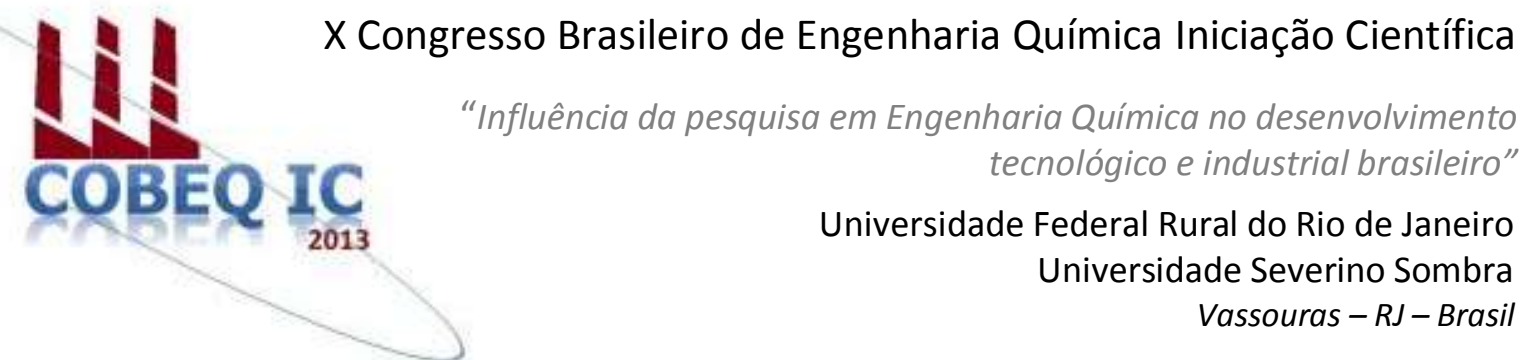

\title{
AVALIAÇÃO DA REDUÇÃO DE COR E TURBIDEZ NO TRATAMENTO COMBINADO DE LIXIVIADO DE ATERRO SANITÁRIO E ESGOTO DOMÉSTICO POR PROCESSO PACT ${ }^{\circledR}$
}

\author{
PEREIRA $^{1}$, B. C.; SOUSA ${ }^{2}$, D. A. G.; FERREIRA ${ }^{2}$, A. S. M. B.; BARBOSA ${ }^{2}$, A. B.; \\ SANTANA $^{2}$, T. O. M.; HONORATO ${ }^{2}$, T. K. N.; NASCENTES ${ }^{3}$, A. L. \\ ${ }^{1}$ Aluna do DEQ/UFRRJ $\quad{ }^{2}$ Aluno do IT/DE/UFRRJ ${ }^{3}$ Professor do IT/DE/UFRRJ \\ Departamento de Engenharia - Universidade Federal Rural do Rio de Janeiro \\ Endereço - UFRRJ, BR 465, km 07, Seropédica, CEP. 23.890-000, RJ, \\ email: alexandrelioi@gmail.
}

\begin{abstract}
RESUMO - Obter altas eficiências em sistemas de tratamento de lixiviado de aterro sanitário consiste num grande desafio para a engenharia. Diversas estações de tratamento de esgoto recebem lixiviado para tratamento combinado, porém, o lixiviado possui compostos de baixa biodegradabilidade e sua inserção em processos como os lodos ativados implica num grande choque de carga. O processo PACT® combina o uso do carvão ativado em pó com o processo de lodos ativados. Nesta pesquisa objetiva-se avaliar a redução de cor e turbidez no tratamento combinado de lixiviado de aterro sanitário e esgoto doméstico por processo PACT®. Para tal, foram montados 2 reatores em batelada. Os reatores foram alimentados com misturas de $2 \%$ de lixiviado/esgoto, com tempo de retenção hidráulica de 30 horas, idade de lodo de 28 dias e inoculados com lodo biológico adaptado. O reator 1 funcionou como PACT® e o reator 2 como lodos ativados. Foram monitorados os parâmetros cor e turbidez. No R1, os valores médios de cor e turbidez encontrados no efluente tratado foram de $321,2 \mathrm{uH}$ e 22,3 uT, enquanto no R2 foram 461,2 uH e 19,4 uT, respectivamente O PACT® melhorou a eficiência de redução da cor no efluente tratado, sem influenciar nos resultados de turbidez.
\end{abstract}

Palavras chave: chorume, carvão ativado, co-tratamento.

\section{INTRODUÇÃO}

O crescimento populacional e industrial implica na inserção de grandes volumes de resíduos no ambiente. Mudanças nos processos de produção e no estilo de vida da sociedade tem tornado a composição desses resíduos ainda mais complexa. É comum o emprego de aterros sanitários para o tratamento e a disposição final dos resíduos. Este é um método que lança mão de princípios de engenharia para realizar o confinamento dos resíduos sólidos à menor área possível e reduzindo seu volume. Os mesmos são cobertos com uma camada de terra na conclusão da jornada de trabalho ou em intervalos menores, se necessário (IPT, 1995). Apesar de ser uma técnica de baixos custos e 
vastamente aplicada, ela gera um subproduto indesejável conhecido como lixiviado ou chorume. $\mathrm{O}$ lixiviado gerado em aterros sanitários é decorrente da percolação, através das camadas do aterro, de líquidos de origem externa: águas pluviais, escoamento superficial, águas subterrâneas, da água gerada no processo de decomposição dos resíduos orgânicos (catalisada por ação enzimática e por bactérias decompositoras) e da umidade presente nos próprios resíduos sólidos. Neste processo de percolação de líquidos através das camadas de resíduos no aterro, as substâncias orgânicas e inorgânicas são solubilizadas, conferindo ao líquido gerado uma composição bastante variável (Tchobanoglous et al., 1993).

Segundo Del Borgui et al. (2003), experiências de tratamento combinado de lixiviado em estações de tratamento de esgoto (ETE's), têm obtido êxito. O que demonstra que essa técnica surge como uma alternativa promissora.

O tratamento no qual o lixiviado é incorporado é o de Lodos Ativados. No reator ocorrem reações bioquímicas de remoção da matéria. A biomassa consome o substrato presente no esgoto bruto para se desenvolver. No decantador secundário se passa a sedimentação dos sólidos (biomassa), contribuindo para que o efluente final saia clarificado. Esse sistema possui alta eficiência, visto que os sólidos sedimentados no fundo do decantador são recirculados para o reator, aumentando a concentração de biomassa no mesmo (VON SPERLING 2002).

Segundo Ferreira et al. (2001), os tratamentos biológicos apresentam baixa eficiência em função do lixiviado apresentar compostos com elevada resistência à biodegradação, sobretudo quando provém de aterros mais antigos, cujos sistemas de tratamento geralmente demandam uma etapa inicial com o objetivo de diminuir a recalcitrância do lixiviado.

Além deste fator, a inserção de lixiviado em processos como os lodos ativados implica num grande choque de carga. $\mathrm{O}$ carvão ativado em pó associado ao processo de lodos ativados surge como um coadjuvante que pode oferecer maior eficiência ao processo, auxiliando na remoção de cor e de poluentes recalcitrantes e também conferindo estabilidade frente a choques de carga.

O processo PACT ${ }^{\circledR} \quad$ (Powdered Activated Carbon Treatment) consiste na associação sinérgica entre a oxidação biológica promovida pelo processo de lodos ativados e a adsorção física inerente ao carvão ativado.

O objetivo deste trabalho foi avaliar o desempenho do processo PACT® na redução de cor e turbidez no tratamento combinado de lixiviado de aterro sanitário e esgoto doméstico.

\section{MATERIAIS E MÉTODOS}

Para a realização deste trabalho, foram montados 2 reatores em batelada em escala de bancada, conforme a Figura 1.

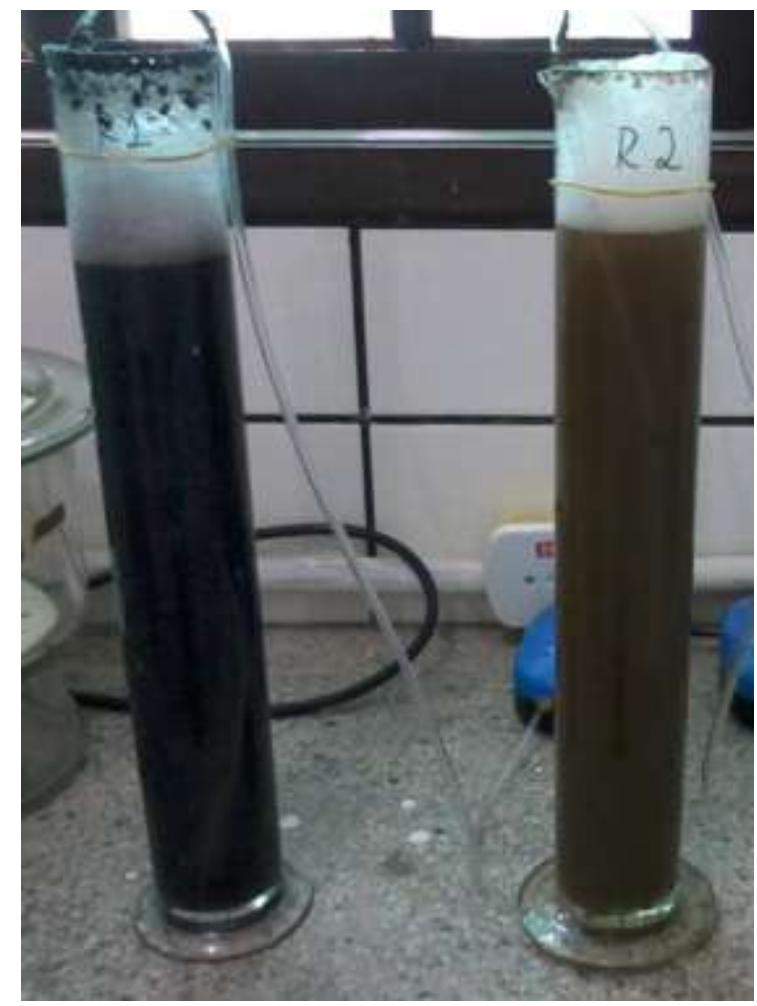

Figura 1 - Esquema dos reatores.

Os reatores foram alimentados com misturas de $2 \%$ de lixiviado/esgoto, sendo utilizado esgoto sintético para evitar as grandes variações de DQO, DBO observadas no esgoto oriundo das estações de tratamento. $\mathrm{Na}$ Tabela 1 está descrita a composição do esgoto sintético. 
Tabela 1 - Composição do esgoto sintético.

\begin{tabular}{lc}
\hline \multicolumn{1}{c}{ Reagente } & $\begin{array}{c}\text { Concentração } \\
(\mathbf{m g} / \mathbf{L})\end{array}$ \\
\hline Peptonas de caseína & 360 \\
Extrato de carne & 250 \\
Ureia & 100 \\
$\begin{array}{l}\text { Fosfato monobásico de } \\
\text { potássio }\end{array}$ & 26 \\
Cloreto de sódio & 14 \\
$\begin{array}{l}\text { Cloreto de cálcio di- } \\
\text { hidratado }\end{array}$ & 8 \\
$\begin{array}{l}\text { Sulfato de magnésio } \\
\text { hepta-hidratado }\end{array}$ & 4 \\
\hline
\end{tabular}

O tempo de retenção hidráulica empregado foi de 30 horas, conforme mostra a Equação (1).

$$
\mathrm{TRH}=\frac{\mathrm{V}}{\mathrm{Q}}
$$

O volume dos reatores utilizados foi de $1000 \mathrm{~mL}$ e a vazão foi de $800 \mathrm{~mL} /$ dia. Assim, substituindo esses valores na Equação (1), temos $\mathrm{TRH}=1,25 \mathrm{dia}$, ou multiplicando por 24 horas, $\mathrm{TRH}=30$ horas.

Segundo VON SPERLING, 2002, para lodos ativados operando com aeração prolongada, recomenda-se manter a idade do lodo entre 18 e 30 dias. Os reatores foram inoculados com lodo biológico adaptado pelo período de uma semana. O lixiviado utilizado foi proveniente do Aterro Sanitário Dois Arcos, localizado no município de São Pedro da Aldeia, Rio de Janeiro.

O carvão empregado foi o a da marca Carbomafra, um carvão nacional de origem vegetal. Suas características podem ser observadas na Tabela 2.

Tabela 2 - Características do carvão Carbomafra.

\begin{tabular}{lc}
\hline \multicolumn{1}{c}{$\begin{array}{c}\text { Parâmetros de } \\
\text { Caracterização }\end{array}$} & Resultados \\
\hline $\begin{array}{l}\text { Área BET } \\
\text { Área de microporo }\end{array}$ & $726,68 \mathrm{~m} 2 / \mathrm{g}$ \\
\hline $\begin{array}{l}\text { Área externa } \\
\text { Volume de } \\
\text { microporo }\end{array}$ & $560,59 \mathrm{~m} 2 / \mathrm{g}$ \\
$\begin{array}{l}\text { Tamanho de } \\
\text { microporo }\end{array}$ & $166,08 \mathrm{~m} 2 / \mathrm{g}$ \\
\hline
\end{tabular}

$\mathrm{O}$ reator 1 funcionou como PACT® e o reator 2 como lodos ativados. No reator 1 houve a reposição diária do carvão ativado em pó CAP ( $0,05 \mathrm{~g})$ que era removido juntamente com o volume do lodo descartado $(15 \mathrm{~mL})$, de modo a se manter uma concentração de CAP constante. Também diariamente, era feita a interrupção da aeração durante uma hora e 800 $\mathrm{mL}$ do sobrenadante eram retirados dos reatores sendo substituídos por $800 \mathrm{~mL}$ de alimentação. Na Figura 2 é possível observar os reatores com uma hora de decantação.

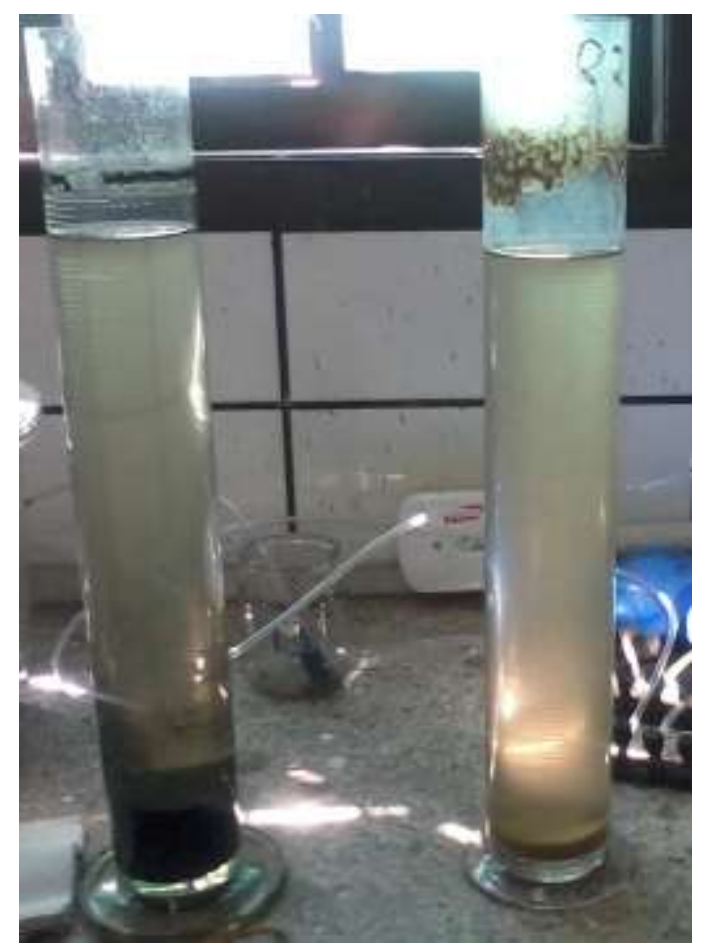

Figura 2 - Reatores ao final de uma hora de decantação.

\section{RESULTADOS E DISCUSSÃO}

Foram monitorados os parâmetros cor e turbidez da alimentação e do efluente dos reatores. Na Tabela 3 está a caracterização da alimentação.

Tabela 3 - Caracterização da alimentação.

\begin{tabular}{lc}
\hline \multicolumn{1}{c}{ Parâmetro } & Resultado \\
\hline DQO $(\mathrm{mg} / \mathrm{L})$ & 535,7 \\
$\mathrm{pH}$ & 7,42 \\
Condutividade $(\mu \mathrm{S} / \mathrm{cm})$ & 921,7 \\
Cor $(\boldsymbol{u H})$ & $\mathbf{1 . 4 4 4}$ \\
Turbidez $(\boldsymbol{u T})$ & $\mathbf{7 0}$ \\
\hline
\end{tabular}


Os valores médios para cor e turbidez encontrados no efluente bruto foram de 1444 $\mathrm{uH}$ e $70 \mathrm{uT}$, respectivamente. No R1, os valores médios de cor e turbidez encontrados no efluente tratado foram de $133,3 \mathrm{uH}$ e 4,1 uT, enquanto no R2 foram 171,7 uH e 4,3 uT, respectivamente. Estes resultados foram representados na forma de Box Plot, como mostrado nas Figura 3 e 4.

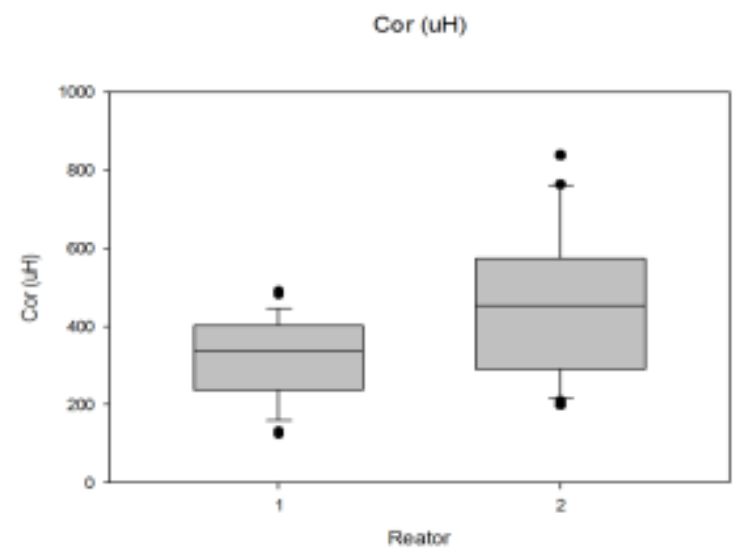

Figura 3 - Box Plot com o parâmetro cor dos reatores $\mathbf{R} 1$ e $\mathbf{R} 2$

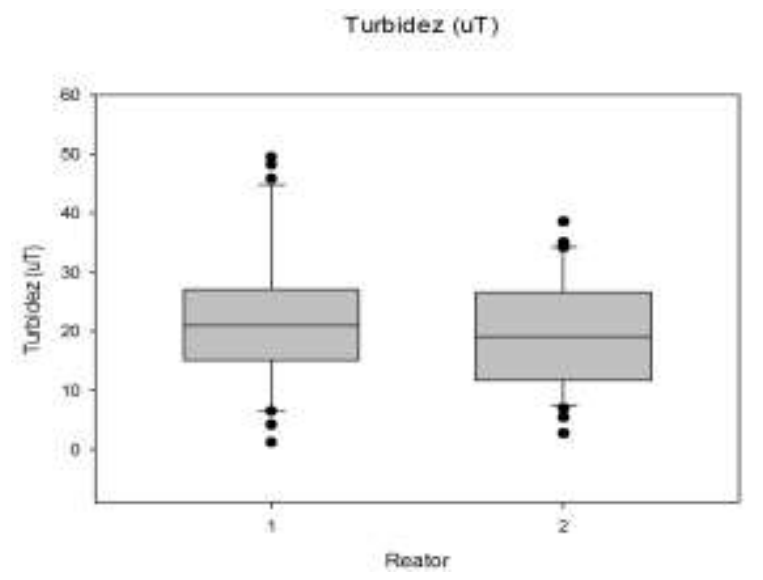

Figura 4 - Box Plot com o parâmetro turbidez dos reatores $\mathrm{R} 1$ e $\mathbf{R} 2$

Para o parâmetro cor foi obtida eficiência de $77,8 \%$ com o uso do PACT® e $68,1 \%$ com o reator que operou como lodos ativados. Para o parâmetro turbidez, as eficiências foram de 68,2,\% com o uso do PACT® e 72,3\% com lodos ativados.

\section{CONCLUSÕES}

O PACT ${ }^{\circledR}$ obteve melhor resultado de eficiência para remoção de cor, mas não influenciou de maneira significativa nos resultados de turbidez. Tal resultado se justifica pelo fato de o carvão adsorver preferencialmente os sólidos dissolvidos, os quais conferem cor à amostra. A inserção de carvão ao sistema acaba por aumentar a concentração de sólidos em suspensão, reflexo disso é a diminuição na eficiência de remoção de turbidez.

\section{NOMENCLATURA}

BET - Brunauer, Emmett e Teller

CAP - Carvão Ativado em Pó

DBO - Demanda Bioquímica de Oxigênio

DQO - Demanda Química de Oxigênio

PACT ${ }^{\circledR}$ - Powdered Activated Carbon

Treatment

$\mathrm{pH}$ - Potencial Hidrogeniônico

Q - Vazão Volumétrica

R1 - Reator 1

R2 - Reator 2

TRH - Tempo de Retenção Hidráulica

$\mathrm{uH}$ - Unidade Hazen

uT - Unidade de Turbidez

$\mathrm{V}$ - Volume

\section{REFERÊNCIAS}

DEL BORGHI, A.; BINAGHI, L.; CONVERTI, A.; DEL BORGHI, M. Combined Treatment of Leachate from Sanitary Landfill. Chem. Biochem. Eng. Q. 17 (4) 277-283, 2003.

FERREIRA, J.A. et al. Uma revisão das técnicas de tratamento de chorume e a realidade do Estado do Rio de Janeiro. In: 21. ${ }^{\circ}$ Congresso Brasileiro de Engenharia Sanitária e Ambiental, 2001.

INSTITUTO DE PESQUISAS TECNOLÓGICAS DO ESTADO DE SÃO PAULO (IPT). Lixo Municipal: manual de gerenciamento integrado. São Paulo: IPT/CEMPRE. 1995. 278p.

TCHOBANOGLOUS, G.; THEISEN, H.; VIGIL, S.A. Integrated solid waste management: Engineering principles and management issues. McGraw Hill, 1993.

VON SPERLING, M., 2002, Princípios do tratamento biológico de águas residuárias, v. 4-Lodos Ativados, DESA, UFMG, Belo Horizonte, Brasil. 


\section{AGRADECIMENTOS}

À Fundação de Amparo à Pesquisa do

Estado do Rio de Janeiro (FAPERJ). 